\title{
Knowledge, attitudes and practice of adverse drug reaction monitoring among physicians in India
}

\author{
Sukanta Sen ${ }^{1 *}$, Sk. Rafikul Rahaman², Dattatreyo Chatterjee ${ }^{3}$, Shatavisa Mukherjee ${ }^{4}$, \\ Somnath Mondal ${ }^{4}$, S. K. Tripathi ${ }^{4}$
}

\begin{abstract}
${ }^{1}$ Department of Pharmacology,
${ }^{2}$ Department of Pediatrics,

ICARE Institute of Medical

Sciences and Research,

Banbishnupur, Purba Medinipur,

Haldia 721645, West Bengal,

India

${ }^{3}$ Department of Pharmacology,

R. G. Kar Medical College,

Kolkata 700004, West Bengal,

India

${ }^{4}$ Department of Clinical and

Experimental Pharmacology,

Calcutta School of Tropical

Medicine, Kolkata 700073,

West Bengal, India

Received: 08 April 2017

Accepted: 02 May 2017

*Correspondence to:

Dr. Sukanta Sen,

Email: drsukant@gmail.com
\end{abstract}

Copyright: (C) the author(s), publisher and licensee Medip Academy. This is an openaccess article distributed under the terms of the Creative Commons Attribution NonCommercial License, which permits unrestricted noncommercial use, distribution, and reproduction in any medium, provided the original work is properly cited.

\begin{abstract}
Background: Underreporting of ADRs still remains a major obstacle in the complete success of pharmacovigilance programs. In order to improve ADR monitoring, it is thus imperative to assess the current knowledge, attitude, and practices of doctors. Therefore, the primary objective of this study was to evaluate the knowledge, attitude, and practices (KAP) of the healthcare professionals about pharmacovigilance in various tertiary care government teaching hospital vis-a-vis private clinics in West Bengal.

Methods: A cross sectional, questionnaire based survey was conducted among healthcare practitioners in several tertiary care government set-ups and private set-ups in the state of West Bengal (India). The study instrument was a prevalidated structured questionnaire designed to obtain information on the knowledge of the ADRs reporting, the attitudes towards the reporting, and the factors that in practice could hinder the reporting among the doctors.

Results: About $89.62 \%$ public practitioners correctly spotted the WHO definition for pharmacovigilance, while $77.5 \%$ of the private practitioners did the same. Only $19.81 \%$ of the public practitioners documented a suspected $\mathrm{ADR}$ in any surveillance form, while there were only $3.75 \%$ private practitioners who documented it. About $59.43 \%$ of the physicians in government hospitals published an ADR case report in any medical journal, while $81.25 \%$ private practitioners did no.

Conclusions: Study revealed lack of time, incentive less extra work load being major factors responsible for ADR underreporting. In order to improve ADR reporting, continuous medical education, training and proper sensitization of healthcare professionals can help combating the existing scenario and promising an improved tomorrow. The PvPI should be widely publicized in the visual and print media to make health professionals, as well as the general population at large aware of its presence and scope. Pharmacovigilance should be integrated in undergraduate and postgraduate medical courses.
\end{abstract}

Keywords: Attitude, Practice, Adverse ADR monitoring, Drug reaction, Knowledge, Physician, Pharmacovigilance

\section{INTRODUCTION}

Adverse drug reactions (ADRs) are global problems having a major impact on public health. Adverse drug reaction $(A D R)$ is defined by World Health Organization (WHO) as "a response to a drug which is noxious and unintended, and which occurs at doses normally used in man for the prophylaxis, diagnosis or therapy of disease or for the modification of physiological function". ${ }^{1}$ ADRs have medical as well as economic consequences, leading to increased patient morbidity and mortality., ${ }^{2,3}$ 
This has given rise to "pharmacovigilance", which is defined as the science and activities relating to the detection, assessment, understanding, and prevention of adverse effects of drugs, or any other drug-related problems. ${ }^{4}$ The burden of ADRs is expected to be even higher in developing countries due to extensive prevalence of selfmedication, fake and adulterated medicine. ${ }^{5,6}$

Spontaneous monitoring is the foundation of a successful pharmacovigilance. In developed countries, the contribution of healthcare professionals is significant in this regard and has enormously contributed to signal detection of previously undetected ADRs. However, in India, spontaneous monitoring has resulted in lower rates of reporting, and so the Indian contribution to the World Health Organization (WHO) Uppsala Monitoring Centre database is much meager. ${ }^{7}$ A study from South India revealed that $0.7 \%$ of hospital admissions were due to ADRs and a total of $3.7 \%$ hospitalized patients experienced ADRs, of which death accounts for $1.3 \% .^{8}$ The magnitude was even higher in the emergency department were $6.89 \%$ of admissions were due to ADRs. ${ }^{9}$

To transform the pharmacovigilance activity into practices for enhancing patient safety, more ADR monitoring centres (AMC) are being set up across the country under pharmacovigilance program of India (PvPI). The PvPI was launched with a broad objective in patient safety for more than one billion people of India. In July, 2010, the Central Drug Standard Control organization, New Delhi initiated a nationwide pharmacovigilance program under aegis of Ministry of health and Family welfare, Government of India with All India Institute of Medical Sciences (AIIMS), New Delhi as a National Coordinating Centre (NCC) to monitor ADR. ${ }^{10}$

Providing information on suspected ADRs is as much a moral duty for the healthcare professionals as other aspects of patient care. Spontaneous ADR reporting is important to monitor known and unknown adverse effects of medicines. Furthermore, spontaneous reporting of ADRs has played a most important role in the detection of serious and unusual ADRs during marketing of the drug in actual practicing in the market. This has led to the withdrawal of drugs like rofecoxib, cisapride, terfenadine, etc. in the past. ${ }^{11,12}$ The ADR reporting rate in India is below $1 \%$ compared to the worldwide rate of $5 \% .{ }^{13}$ One of the reasons for such low reporting rate in India may be attributed to a lack of knowledge and sensitization towards pharmacovigilance and ADR among health care professional. ${ }^{14}$ Lack of awareness about the detection, communication, and reporting of ADRs is a principle cause of underreporting. ${ }^{15}$ Practitioners may even underreport ADRs due to financial incentives, fear of litigation, and ambition to publish. ${ }^{16}$
In order to improve ADR monitoring, it is thus imperative to assess the current knowledge, attitude, and practices of doctors. Therefore the primary objective of this study was to evaluate the knowledge, attitude, and practices (KAP) of the healthcare professionals about pharmacovigilance in various tertiary care government teaching hospital vis-a-vis private clinics in West Bengal. Although many studies in India have evaluated the KAP of pharmacovigilance among the healthcare professionals, it is imperative to compare the awareness level among the public vis-a-vis private set ups, such as to address the issue of underreporting of ADRs and assess the causation of it.

\section{METHODS}

A cross sectional, questionnaire based survey was conducted among healthcare practitioners in several tertiary care government set-ups and private set-ups in the state of West Bengal (India). The study instrument was a pre-validated structured questionnaire designed to obtain information on the knowledge of the ADRs reporting, the attitudes towards the reporting, and the factors that in practice could hinder the reporting among the doctors. Suggestions on the possible ways to improve the ADR reporting were welcome. Participants were explained the purpose of study and were requested to complete and return the questionnaire immediately. Data were analyzed using SPSS 17 software. $\mathrm{P}<0.05$ was considered as significant.

\section{RESULTS}

\section{Demographic details}

The demographic details of the healthcare professionals are summarized in Table 1.

\section{Response rate}

Among 240 questionnaires distributed equally, only 186 duly filled completed questionnaires were received back (response rate $=77.5 \%$ ); out of which 106 were from public practitioners and 80 were from private practitioners.

\section{Knowledge}

The responses to the knowledge-based questions in this study indicate an average degree of knowledge regarding diverse aspects of pharmacovigilance. About 89.62\% public practitioners correctly spotted the WHO definition for pharmacovigilance, while $77.5 \%$ of the private practitioners did the same. Central Drug Standard Control Organization (CDSCO) was identified as the national body responsible for ADR monitoring by $92.45 \%$ of public responders and $70 \%$ private responders. Awareness regarding "Pharmacovigilance Programme of India" (PvPI) was found among 62.26\% of the physicians from the government set-up only. The awareness was 
markedly absent in case of $85 \%$ of the private practitioners. Majority of responders from both group believed healthcare professionals or doctors to be the primary individuals responsible for ADR reporting. While; there were other responders from the population (33-36\%) who believed patients, pharmacists, nurses and doctors to be all responsible for reporting ADRs. 63.21\% of the pubic practitioners believed that all ADRs needs to be reported while $45 \%$ of the private practitioners felt that only serious ADRs gain that importance.

Table 1: Demographic characteristics of the healthcare professionals under present study.

\begin{tabular}{|c|c|c|}
\hline \multirow[t]{2}{*}{ Particulars } & $\begin{array}{l}\text { Public } \\
\text { practitoners }\end{array}$ & $\begin{array}{l}\text { Private } \\
\text { practitioners }\end{array}$ \\
\hline & No $(\%)$ & No $(\%)$ \\
\hline Mean age (in years) & 37.41 & 41.26 \\
\hline \multicolumn{3}{|l|}{ Sex } \\
\hline Male & $81(76.41)$ & $53(66.25)$ \\
\hline Female & $25(23.5)$ & $27(33.75)$ \\
\hline \multicolumn{3}{|c|}{ Educational qualifications } \\
\hline UG & $21(19.81)$ & $0(0)$ \\
\hline PG diploma & $15(14.15)$ & $9(11.25)$ \\
\hline PG degree & $66(62.26)$ & $65(81.25)$ \\
\hline Others & $3(2.83)$ & $6(7.5)$ \\
\hline \multicolumn{3}{|l|}{ Professional occupation } \\
\hline $\begin{array}{l}\text { General practitioner / } \\
\text { family physician }\end{array}$ & $3(2.83)$ & $24(30)$ \\
\hline Specialist doctor & $43(40.57)$ & $56(70)$ \\
\hline $\begin{array}{l}\text { Academician / } \\
\text { researcher }\end{array}$ & $21(19.8)$ & $0(0)$ \\
\hline $\begin{array}{l}\text { Post doctoral/ post } \\
\text { graduate }\end{array}$ & $39(36.79)$ & $0(0)$ \\
\hline Industry employed & $0(0)$ & $0(0)$ \\
\hline Others & $0(0)$ & $0(0)$ \\
\hline \multicolumn{3}{|c|}{ Which sector do you work with? } \\
\hline $\begin{array}{l}\text { Independent private } \\
\text { practitioner }\end{array}$ & $3(2.83)$ & $18(22.5)$ \\
\hline $\begin{array}{l}\text { Private hospital/ } \\
\text { nursing home }\end{array}$ & $3(2.83)$ & $62(77.5)$ \\
\hline Government Sector & $102(96.22)$ & $0(0)$ \\
\hline $\begin{array}{l}\text { Public Sector } \\
\text { Undertaking }\end{array}$ & $0(0)$ & $0(0)$ \\
\hline $\begin{array}{l}\text { Non government / } \\
\text { Charitable organisation }\end{array}$ & $2(1.88)$ & $0(0)$ \\
\hline Industry & $0(0)$ & $0(0)$ \\
\hline Others & $0(0)$ & $0(0)$ \\
\hline
\end{tabular}

Majority (50.94\%) of the public responders believed that the knowledge and information about ADR were primarily generated from preclinical toxicity testing, clinical trials, post marketing surveillance (PMS) studies and spontaneous ADR reporting from healthcare professionals. Around $45 \%$ of the private practitioners regarded spontaneous ADR reporting as the sole source of generation of information regarding ADR.

\section{Practice}

Only $19.81 \%$ of the public practitioners documented a suspected ADR in any surveillance form, while there were only $3.75 \%$ private practitioners who documented it. About $59.43 \%$ of the physicians in government hospitals published an ADR case report in any medical journal, while $81.25 \%$ private practitioners did not. Information about ADRs were mainly gathered from text books, internet, scientific journals, verbal communication with colleagues, reference books on drug information, promotional materials and product launch meetings. $56.60 \%$ of public responders and $58.75 \%$ private responders reported "sometimes" sensitizing their patients regarding ADRs on prescribing medicines. Majority i.e. $43.39 \%$ of public practitioners reported "sometimes" coming across an ADR in clinical practice while $37.5 \%$ of private practitioners reported "rarely" facing an ADR in their practice. $36.7 \%$ of public responders received some sort of formal training on ADR monitoring while only $3.7 \%$ of private practitioners received the same.

\section{Attitude}

Majority of the responders from both groups agreed that ADR reporting is a prime professional responsibility of a doctor and it should voluntarily be reported to a local ADR monitoring centre from where they expect a proper feedback. Diffidence about whom to report was mostly cited as the primary barrier in ADR reporting in case of both government and private responders. However, lack of attitude, concern about regarding it as a medical negligence were also allied barriers cited.

Study revealed lack of time, incentive less extra work load being major factors responsible for ADR underreporting; however serious and unusual reactions may encourage one to report the same. Majority believed that ever evolving modern technologies can facilitate ADR reporting in India. Strategies towards improvement in ADR reporting should be undertaken. Easy and accessible reporting mechanism followed by continuous medical education, training and proper sensitization were regarded as prime strategies.

\section{DISCUSSION}

ADR-monitoring and reporting programs encourage ADR surveillance, facilitate ADR documentation, promote the reporting of ADRs, provide a mechanism for monitoring the safety of drug use in high-risk patient populations, and stimulate the education of health professionals regarding potential ADRs. A comprehensive, ongoing ADR program should include mechanisms for monitoring, detecting, evaluating, documenting, and reporting ADRs as well as intervening and providing educational feedback to prescribers, other health care professionals, and patients. 
Table 2: Knowledge related parameters regarding pharmacovigilance and ADR monitoring.

\begin{tabular}{|c|c|c|}
\hline Particulars & Public practitoners & Private practitioners \\
\hline & No $(\%)$ & No $(\%)$ \\
\hline \multicolumn{3}{|l|}{$\begin{array}{l}\text { Which of the following best represents the definition } \\
\text { for pharmacovigilance }\end{array}$} \\
\hline Alertness about the safety and tolerability of prescribed medicine & $8(7.55)$ & $12(15)$ \\
\hline $\begin{array}{l}\text { The science and activities relating to detection, assessment, } \\
\text { understanding and prevention of adverse drug reactions and drug } \\
\text { related problems }\end{array}$ & $95(89.62)$ & $62(77.5)$ \\
\hline Pre-marketing safety evaluation of drugs & $3(2.83)$ & $6(7.5)$ \\
\hline \multicolumn{3}{|l|}{ Which organization in India is responsible for ADR monitoring } \\
\hline Medical Council of India (MCI) & $3(2.83)$ & $9(11.25)$ \\
\hline Indian Council of Medical Research (ICMR) & $3(2.83)$ & $9(11.25)$ \\
\hline Central Drugs Standard Control Organization (CDSCO) & $98(92.45)$ & $56(70)$ \\
\hline $\begin{array}{l}\text { National Accreditation Board for Hospitals and Healthcare Providers } \\
\text { (NABH) }\end{array}$ & $2(1.88)$ & $6(7.5)$ \\
\hline Don’t know & $2(1.88)$ & \\
\hline \multicolumn{3}{|l|}{ Are you aware of the Pharmacovigilance Programme of India' (PvPI) } \\
\hline Yes & $66(62.26)$ & $12(15)$ \\
\hline No & $40(37.73)$ & $68(85)$ \\
\hline \multicolumn{3}{|l|}{ Who can/ should report an ADR } \\
\hline Patients & $2(1.88)$ & \\
\hline Pharmacists & $7(6.60)$ & $6(7.5)$ \\
\hline Nurses & $7(6.60)$ & $6(7.5)$ \\
\hline Doctors & $57(53.77)$ & $47(58.75)$ \\
\hline All of the above & $39(36.79)$ & $27(33.75)$ \\
\hline Don't know & $7(6.60)$ & $6(7.5)$ \\
\hline \multicolumn{3}{|l|}{ Which ADRs should be reported } \\
\hline All ADRs & $67(63.21)$ & $24(30)$ \\
\hline Only serious ADRs & $27(25.47)$ & $36(45)$ \\
\hline ADRs to new drugs only & $15(14.15)$ & $18(22.5)$ \\
\hline Don't know & & $6(7.5)$ \\
\hline \multicolumn{3}{|c|}{ How do you think the knowledge and information about ADRs are generated? } \\
\hline Preclinical toxicity testing & $4(3.77)$ & $3(3.7)$ \\
\hline Clinical trials & $20(18.86)$ & $21(26.25)$ \\
\hline Post marketing surveillance (PMS) studies & $28(26.41)$ & $30(37.5)$ \\
\hline Spontaneous reporting of ADRs by health care professional & $36(33.96)$ & $36(45)$ \\
\hline All of the above & $54(50.94)$ & $30(37.5)$ \\
\hline Don’t know & $3(2.83)$ & $6(7.5)$ \\
\hline \multicolumn{3}{|l|}{ Awareness regarding consumer ADR reporting helpline } \\
\hline Yes & $28(26.42)$ & $5(6.25)$ \\
\hline No & $78(73.58)$ & $75(93.75)$ \\
\hline \multicolumn{3}{|l|}{ Is there any nearby ADR reporting and monitoring centre in your knowledge? } \\
\hline \multicolumn{3}{|l|}{ Yes } \\
\hline No & & \\
\hline
\end{tabular}

Additionally, ADR programs should focus on identifying problems leading to ADRs, planning for positive changes, and measuring the results of these changes. Positive outcomes resulting from an ADR program should be emphasized to support program growth and development. ${ }^{17}$ Spontaneous reporting of ADR is the most essential pre-requisite in maintaining patient safety.
Being the basic component of national and international drug safety evaluation in post-approval phase, it may detect previously unrecognized adverse reactions and identify risk factors predisposing drug toxicity thereby investigating the causality. Various studies depict the incidence of ADR to be $2.4-6.5 \%$ in western countries, with only $6-10 \%$ of all ADRs being reported. ${ }^{18}$ 
Table 3: Practice related parameters regarding pharmacovigilance and ADR monitoring.

\begin{tabular}{|lll|}
\hline Particulars & Public practitoners & Private practitioners \\
\hline & No $(\%)$ & No (\%) \\
\hline Have you ever documented a suspected ADR in any surveillance form & & $3(3.75)$ \\
\hline Yes & $21(19.81)$ & $77(96.25)$ \\
\hline No & $85(80.19)$ & \\
\hline Have you ever published an ADR case report(s) in any medical journal & $15(18.75)$ \\
\hline Yes & $63(59.43)$ & $65(81.25)$ \\
\hline No & $42(39.62)$ & $0(0)$ \\
\hline Don't know & $2(1.88)$ & \\
\hline Where from do you gather information about ADRs & & $41(51.25)$ \\
\hline Colleagues & $67(63.21)$ & $68(85)$ \\
\hline Text books & $96(90.56)$ & $24(30)$ \\
\hline Reference books on drug information & $46(43.39)$ & $0(0)$ \\
\hline Indian Pharmacopeia & $7(6.60)$ & $0(0)$ \\
\hline Medical representatives & $11(10.38)$ & $12(15)$ \\
\hline Promotional materials & $17(16.04)$ & $36(45)$ \\
\hline Scientific journals & $67(63.21)$ & $36(45)$ \\
\hline Internet & $70(66.04)$ & $6(7.5)$ \\
\hline Drug promotion forum/product launch meetings & $17(16.04)$ & \\
\hline While prescribing medicines, do you tell your patients about ADRs? & & $24(30)$ \\
\hline Always & $3(2.83)$ & $47(58.75)$ \\
\hline Sometimes & $60(56.60)$ & $9(11.25)$ \\
\hline Rarely & $20(18.86)$ & $0(0)$ \\
\hline Never & $0(0)$ & \\
\hline How frequently do you ever come across an ADR in your clinical practice? & $9(11.25)$ \\
\hline Very frequently & $3(2.83)$ & $21(26.25)$ \\
\hline Often & $24(22.64)$ & $21(26.25)$ \\
\hline Sometimes & $46(43.39)$ & $30(37.5)$ \\
\hline Rarely & $32(30.18)$ & $3(3.7)$ \\
\hline Never & $3(2.83)$ & $3(3.7)$ \\
\hline Have you received any formal training/teaching on ADR monitoring? & & $77(96.25)$ \\
\hline Yes & $39(36.7)$ & \\
\hline No & $67(63.21)$ & \\
\hline & & \\
\hline
\end{tabular}

Issues and challenges in pharmacovigilance in India are gross underreporting of ADR mainly due to lack of adequately skilled resources and inadequate awareness of pharmacovigilance among physicians. ${ }^{19,20}$ The present study was thus aimed to analyze the pharmacovigilance knowledge, ADR reporting behavior, and deterrents for ADR reporting, among pool of healthcare physicians in West Bengal, India. The study evaluated the knowledge, attitude and practices (KAP) of the healthcare professionals about pharmacovigilance in various tertiary care teaching hospital vis-à-vis private clinics in West Bengal.

On equally distributing the questionnaires among a pool of healthcare professionals from both public and private set-up; response rate was seen higher from the public healthcare practitioners compared to the private ones. Knowledge regarding pharmacovigilance was seen higher among the public practitioners compared to the private ones. Determinants such as ability to correctly spot the WHO definition of Pharmacovigilance, identifying the national body responsible for ADR monitoring, awareness regarding national pharmacovigilance programme were all found to be on higher mark for physicians from government healthcare set-ups. There was a marked absence of sensitization regarding ongoing national pharmacovigilance programme among the private practitioners, which is quite alarming. ${ }^{21}$ The active participation of healthcare practitioners in the pharmacovigilance program can improve the ADR reporting. Responders from both group believed healthcare physicians along with patients, pharmacists and nurses to be responsible for ADR reporting. Majority of the responders from both groups however agreed ADR reporting to be a prime professional responsibility of a doctor towards the society and it should voluntarily be reported to a local ADR monitoring centre from where a proper feedback is expected. 
Table 4: Attitude related parameters regarding pharmacovigilance and ADR monitoring.

\begin{tabular}{|c|c|c|}
\hline Particulars & Public practitoners & Private practitioners \\
\hline & No $(\%)$ & No $(\%)$ \\
\hline \multicolumn{3}{|l|}{ Do you think pharmacovigilance should be taught in detail to healthcare professionals } \\
\hline Yes & $89(83.96)$ & $53(66.25)$ \\
\hline No & $2(1.88)$ & $9(11.25)$ \\
\hline Don't know & $15(14.15)$ & $18(22.5)$ \\
\hline \multicolumn{3}{|l|}{ Do you agree that ADR reporting is a professional responsibility of a doctor? } \\
\hline Yes & $91(85.85)$ & $47(58.75)$ \\
\hline No & $7(6.60)$ & $12(15)$ \\
\hline Don’t Know & $7(6.60)$ & $21(26.25)$ \\
\hline \multicolumn{3}{|l|}{ In your opinion should ADR reporting be } \\
\hline Legal & $12(11.32)$ & $9(11.25)$ \\
\hline Voluntary & $67(63.21)$ & $53(66.25)$ \\
\hline Compulsory & $25(23.58)$ & $15(18.75)$ \\
\hline Remunerated & $15(14.15)$ & $6(7.5)$ \\
\hline \multicolumn{3}{|l|}{ Cannot say } \\
\hline \multicolumn{3}{|l|}{ If yes, to whom should the reporting be done } \\
\hline Hospital Superintendent & $18(16.98)$ & $12(15)$ \\
\hline State Drugs Controller & $11(10.38)$ & $6(7.5)$ \\
\hline Local ADR monitoring centre & $68(64.15)$ & $62(77.5)$ \\
\hline Drugs Control General of India (DCGI) & $7(6.60)$ & $0(0)$ \\
\hline Cannot say & $3(2.83)$ & $0(0)$ \\
\hline \multicolumn{3}{|l|}{ On reporting an ADR do you expect a feedback from the ADR monitoring centre } \\
\hline Yes & $86(81.13)$ & $56(70)$ \\
\hline No & $10(9.43)$ & $9(11.25)$ \\
\hline Cannot say & $10(9.43)$ & $15(18.75)$ \\
\hline \multicolumn{3}{|l|}{ What is the greatest barrier for ADR reporting by physicians in India } \\
\hline Lack of attitude & $46(43.39)$ & $33(41.25)$ \\
\hline Unsure about whom to report & $45(42.45)$ & $39(48.75)$ \\
\hline Worried that it may be viewed as medical negligence & $15(14.15)$ & $9(11.25)$ \\
\hline \multicolumn{3}{|l|}{ Select the factor(s) that discourage(s) you from reporting ADRs } \\
\hline Extra work with no incentive & $40(37.73)$ & $39(48.75)$ \\
\hline Lack of time to report ADR & $57(53.77)$ & $41(51.25)$ \\
\hline Difficult to decide whether ADR has occurred or not & $35(33.01)$ & $18(22.5)$ \\
\hline Lack of access to ADR reporting form & $39(36.79)$ & $18(22.5)$ \\
\hline A single unreported case may not affect ADR database & $17(15.04)$ & $21(26.25)$ \\
\hline Concern that reporting ADRs can be viewed as medical negligence & $9(8.49)$ & $15(18.75)$ \\
\hline \multicolumn{3}{|l|}{ Which of the following may encourage you to report an ADR } \\
\hline If the reaction is serious & $99(93.39)$ & $77(96.25)$ \\
\hline If the reaction is unusual & $92(86.79)$ & $65(81.25)$ \\
\hline If the reaction is to a new product & $53(50)$ & $44(55)$ \\
\hline If the reaction is certainly an ADR & $40(37.73)$ & $30(37.5)$ \\
\hline If the reaction is well recognized for a particular drug & $12(11.32)$ & $3(3.7)$ \\
\hline \multicolumn{3}{|c|}{ Do you think the internet/ gadgets like mobile phones, i-pad, Tablets may ease and facilitate ADR reporting by physicians in India? } \\
\hline Yes & $91(85.54)$ & $59(73.75)$ \\
\hline No & $4(3.77)$ & $6(7.5)$ \\
\hline Don't Know & $11(10.38)$ & $15(18.75)$ \\
\hline \multicolumn{3}{|l|}{ What strategies would you advise towards improving ADRs reporting? } \\
\hline Reporting mechanism of ADR to be made easy and accessible & $86(81.13)$ & $50(62.5)$ \\
\hline Remuneration for ADR submission & $21(19.81)$ & $6(7.5)$ \\
\hline Making reporting by doctors mandatory & $24(22.64)$ & $15(18.75)$ \\
\hline Provide toll free number for reporting & $28(26.41)$ & $15(18.75)$ \\
\hline Continuous medical education, training and sensitization regarding ADR reporting & $82(77.35)$ & $65(81.25)$ \\
\hline Don't know & $2(1.88)$ & $3(3.7)$ \\
\hline \multicolumn{3}{|l|}{ Which of the following may discourage you from reporting an ADR } \\
\hline Mild adverse effect & $89(83.96)$ & $74(92.5)$ \\
\hline Well known reaction & $74(69.81)$ & $56(70)$ \\
\hline Lack of time to report ADR & $29(27.35)$ & $15(18.75)$ \\
\hline No remuneration for reporting & $17(16.04)$ & $6(7.5)$ \\
\hline Difficult to decide whether ADR has occurred or not & $25(23.58)$ & $15(18.75)$ \\
\hline A single unreported case may not affect ADR database & $12(11.32)$ & $3(3.7)$ \\
\hline
\end{tabular}


Notwithstanding the constant endeavor by the Pharmacovigilance Programme of India towards inculcating a culture of ADR monitoring; underreporting is still very prevalent. It is found that only $6-10 \%$ of all ADRs are reported. Such high rate of underreporting is a matter of grave concern which can delay detection of serious ADRs and consequently have a major negative impact on the public health. ${ }^{21}$

PvPI recommends that all ADRs should be reported whether they are serious, non-serious, unusual, new, recognized and certain. However there appears a deficiency in the knowledge and perception of physicians in relation to ADR reporting which should be removed in order to improve spontaneous reporting. ${ }^{22}$ Proper sensitization of the facts that all ADRs need to be reported is necessary. Majority of the responders from public set-ups believed that all ADRs needs to be reported while this awareness was markedly absent among private practitioners. Interdisciplinary discussions can help to drive away these existing misconceptions thereby changing the attitudes of the practitioners. Persisting attitude that single reporting makes no contribution also needs correction, as every single suspected ADR helps in developing data base. Such a change in attitude will be helpful in improving spontaneous ADR reporting in the long run. ${ }^{22}$

Public responders majorly believed that the knowledge and information about ADR were primarily generated from preclinical toxicity testing, clinical trials, post marketing surveillance studies and spontaneous ADR reporting from healthcare professionals. On the contrary, private practitioners regarded spontaneous ADR reporting as the sole source of generation of information regarding $\mathrm{ADR}$. Information about $\mathrm{ADRs}$ were mainly gathered from text books, internet, scientific journals, verbal communication with colleagues, reference books on drug information, promotional materials and product launch meetings. ${ }^{23}$

Around $20 \%$ of the public practitioners documented a suspected ADR in any surveillance form, while there were only $3.75 \%$ private practitioners who documented it. Publishing an ADR case report in any medical journal was found in majority among public practitioners while $81.25 \%$ private practitioners did not.

An important component in patient safety is patient counseling regarding ADRs on prescribing medicines. About $56.60 \%$ of public responders and $58.75 \%$ private responders reported "sometimes" doing so. Majority i.e. $43.39 \%$ of public practitioners reported "sometimes" coming across an ADR in clinical practice while $37.5 \%$ of private practitioners reported "rarely" facing an ADR in their practice. Difficulty in deciding whether an ADR has occurred indicates lack of training in identifying ADRs. Similar responses were observed in higher proportion in a previous study in which concern that report may be wrong and difficulty in deciding ADR occurrence was reported by $81.8 \%$ medical doctors. This deficiency can be removed by having regular interdisciplinary discussions involving clinicians and pharmacologists. Furthermore, during undergraduate and post graduate training program special attention should be given to safety profile of the drugs apart from rational therapeutics. Integrating pharmacovigilance related work in both undergraduates and post graduates curriculum appears to be the need of the hour. ${ }^{24}$ There is always a requirement for constant training and enactment of regulations for ADR reporting among healthcare professionals. $36.7 \%$ of public practitioners received some sort of formal training on ADR monitoring while only $3.7 \%$ of private practitioners received the same.

In a study done by Pimpalkhute in Nagpur, only $35.7 \%$ of respondents, felt that ADR reporting was a professional commitment, which was much lower than that seen in our study. ${ }^{25}$ The uncertainty of whether an ADR had occurred $(35 \%)$ and lack of time $(33 \%)$ were the most important factors discouraging reporting. This finding is similar to studies done by Khan et al, Reddy et al., Chatterjee et al and Datta $S$ et al which also cited a lack of time and determining causality of an ADR as the main reasons for under-reporting. ${ }^{21,26-28}$

Another study in Eastern India also noted good knowledge about ADR reporting, but attitude and perception/practice was an area of concern. ${ }^{27}$ Majority $(84 \%)$ of the respondents in this study had not received any training or attended any educational seminar/workshop/continuing medical education (CME) on pharmacovigilance, though all the respondents did feel a need for the same. Educational interventions have been found to update knowledge and consequently bring a greater degree of awareness to pharmacovigilance..$^{24,28-30}$ Study by Desai CK et al mentioned the reasons cited by prescribers for not reporting ADRs in their study. Lack of knowledge on how $(68 \%)$ and where $(70 \%)$ to report the ADRs and lack of easy access to ADR reporting forms $(49.2 \%)$ were the major factors that discouraged reporting. ${ }^{14}$

Studies reemphasized the fact that there is positive correlation between training of pharmacovigilance and reporting ADR by healthcare professional and it demonstrated that the significance of adverse event monitoring and reporting can be increased through academic interference. Factors such as the unawareness about the method to decide the causal relationship between the ADR can only be removed by regular training. ${ }^{7,32}$ Studies attribute various factors for gross underreporting of ADRs among health professionals which are mainly based on knowledge and perception of health professionals to reporting. Factors like lack of financial incentives, lack of ambition to publish a case series fear of litigation, diffidence that only serious ADRs needs well documentation along with indifference, ignorance and lethargy are attributed factors for underreporting ADRs. Our study cited diffidence about 
whom to report as the primary barrier in ADR reporting in case of both public and private responders. However, lack of attitude, concern about regarding it as a medical negligence were also allied barriers cited. Various studies reveal lack of time, incentive less extra work load being major factors responsible for ADR underreporting; however serious and unusual reactions may encourage one to report the ADR. ${ }^{4,21,28,31-38}$

Human behaviour, knowledge beliefs, and motivation play an important role in ADR reporting. UR might be improved through activities focused on modifying such factors. UR is strongly associated with certain attitudes, that possibly could be modified through educational interventions. ${ }^{39}$ Adverse drug reactions often go unnoticed due to failure of medical teams to recognize adverse drug events or to correlate precisely with biochemical, pathological or radiological abnormality. ${ }^{40}$ Thus, biochemical investigations and diagnostic tools can pick up substantial number of ADRs and can play an important role in PV.

Chopra D et al, showed that nearly two third (66\%) of the doctors knew the definition of ADR. ${ }^{41}$ Only one third (38\%) could correctly define pharmacovigilance and adverse drug event (ADE) respectively. Surprisingly only one tenth of the doctors $(10 \%)$ knew what should be reported. The majority $(74.4 \%)$ felt that reactions to new drug should be reported and also those reactions that are serious and unusual. Only one third (30\%) knew whom to report to and less than half $(30 \%)$ had actually ever reported an ADR.

Majority believed that ever evolving modern technologies can facilitate ADR reporting in India. Strategies towards improvement in ADR reporting should be undertaken. Easy and accessible reporting mechanism followed by continuous medical education, training and proper sensitization were regarded as prime strategies. Adequate knowledge and proper practices of pharmacovigilance and ADR reporting in India will reduce the incidence rate as well as the health care cost of patient, thus ensuring patient safety. Training and workshop on ADR reporting, availability of ADR forms at all departments and monthly case discussion on ADRs can also improve the scenario.

\section{Limitations}

The major limitation of this study was the essentially small number of participants. In addition, some other factors that are associated with self-reporting studies such as accuracy of recall, personal bias could also have affected the results of this study in some ways.

\section{CONCLUSION}

The present study found the awareness about pharmacovigilance and ADR reporting to be on higher mark in case of public healthcare practitioners compared to the private ones. In order to improve ADR reporting, continuous medical education, training and proper sensitization of healthcare professionals can help combating the existing scenario and promising an improved tomorrow. The PvPI should be widely publicized in the visual and print media to make health professionals, as well as the general population at large aware of its presence and scope. Follow-up educational sensitization programs should be conducted at all the centers regularly to reinforce and emphasize the importance of pharmacovigilance and ADR monitoring. Pharmacovigilance should be integrated in undergraduate and postgraduate medical courses. The process of reporting should be made as seamless, hassle free, convenient, and less time-consuming as possible. The fact that majority of respondents agreed that reporting of ADR is necessary and awareness that pharmacovigilance should be taught in detail to healthcare professionals emphasize that they have started to understand the importance of pharmacovigilance.

\section{Funding: No funding sources \\ Conflict of interest: None declared}

Ethical approval: The study was approved by the Institutional Ethics Committee

\section{REFERENCES}

1. International drug monitoring: The role of National Centres. Report No: 498. Geneva, Switzerland: World Health Organization; 1972.

2. Pirmohamed M, James S, Meakin S, Green C, Scott AK, Walley TJ, et al. Adverse drug reactions as cause of admission to hospital: Prospective analysis of 18820 patients. Br Med J. 2004;329:15-9.

3. Lazarou J, Pomeranz BH, Corey PN. Incidence of adverse drug reactions in hospitalized patients: A meta-analysis of prospective studies. JAMA 1998;279:1200-5.

4. The importance of pharmacovigilance. Safety monitoring of medicinal products. Geneva: World Health Organization, WHO Collaborating Centre for International Drug Monitoring; 2002.

5. Strengthening Pharmaceutical Systems (SPS) Programme. Safety of medicines in Sub-Saharan Africa: Assessment of Pharmacovigilance Systems and their performance. Arlington, VA: 2011;143:4.

6. Gala KS, Sinha SR, Mankeshwar R, Desai VK, Gala RS. Evaluation of the pattern of self-medication among the paramedical support staff in a tertiary care hospital. J Young Pharm. 2016;8(1):23-7.

7. Remesh A. Identifying the reasons for under reporting of ADR: A cross sectional survey. Res J Pharm Biol Chem Sci. 2012;3:1379-86.

8. Ramesh M, Pandit J, Parthasarathi G, Adverse drug reactions in south Indian hospital-their severity and cost involved. Pharmacoepidemiol Drug Saf. 2003;12(8):687-92.

9. Patel KJ, Kedia MS, Bajpai D, Mehta SS, Kshirsagar NA, Googtay NJ, Evaluation of the prevalence and economic burden of adverse drug reactions 
presenting to the Medical emergency department of tertiary referral centre: a prospective study. BMC Clin Pharmacol. 2007;7(1):1-5.

10. Ratan JL, Mangala L. An update on the Pharmacovigilance Programme of India. Front Pharmacol. 2015;6:194. Available from: https://www.researchgate.net/publication/282513881 _An_update_on_the_

Pharmacovigilance_Programme_of_India

11. Gupta SK, Text book of pharmacovigilance: Current Methods of Pharmacovigilance. New Delhi: Jaypee brothers Medical Publisher (P) Ltd; 2011:28-38.

12. Ganesan S, Vikneswaran G, Reddy KC, Subrahmanyam DK, Adithan C. A Survey on Knowledge, Attitude and Practice of Pharmacovigilance towards Adverse drug reactions reporting among Doctors and Nurses in a Tertiary Care Hospital in South India. J Young Pharm. 2016;8(4):471-6.

13. Malhotra S, Karan RS, Pandhi P, Jain S. Drug related medical emergencies in the elderly: Role of adverse drug reactions and non-compliance. Postgrad Med J. 2001;77:703-7.

14. Desai CK, Iyer G, Panchal J, Shah S, Dikshit RK. An evaluation of knowledge, attitude, and practice of adverse drug reaction reporting among prescribers at a tertiary care hospital. Perspect Clin Res. 2011;2:129-36.

15. Rehan HS, Vasudev K, Tripathi CD. Adverse drug reaction monitoring: Knowledge, attitude and practices of medical students and prescribers. Natl Med J India. 2002;15:24-6.

16. Gupta P, Udupa A. Adverse drug reaction reporting and pharmacovigilance: knowledge, attitude and perception among resident doctors. J Pharm Sci. 2011;3:1064-9.

17. ASHP guidelines on adverse drug reaction monitoring and reporting. American Society of Hospital Pharmacy. Am J Health Syst Pharm 1995 Feb 15;52(4):417-9.

18. Smith CC, Bennett PM, Pearce HM, Harrison PI, Reynolds DJ, Aronson JK, et al. Adverse drug reactions in a hospital general medical unit meriting notification to committee on safety of medicines. Br J Clin Pharmacol. 1996;42:423-9.

19. Biswas P. Pharmacovigilance in Asia. J Pharmacol Pharmacother. 2013;4(1):S7-19.

20. Rishi RK, Patel RK, Bhandari A. Opinion of physicians towards adverse drug reaction reporting results of pilot study. Journal of Community Medicine and Health. 2012;1:25-9.

21. Khan SA, Goyal C, Chandel N, Rafi M. Knowledge, attitudes, and practice of doctors to adverse drug reaction reporting in a teaching hospital in India: An observational study. J Nat Sci Biol Med. 2013 JanJun;4(1):191-6.

22. Tandon VR, Mahajan V, Khajuria V, Gillani Z. Under-reporting of adverse drug reactions: A challenge for pharmacovigilance in India. Indian $\mathrm{J}$ Pharmacol. 2015;47:65-71.
23. Rishi RK, Patel RK, Bhandari A. Under reporting of ADRs by Medical Practitioner in India- Results of pilot study. Adv Pharmacoepidem Drug Saf. 2012;1(3):1-3.

24. Tabali M, Jeschke E, Bockelbrink A, Witt CM, Willich SN, Ostermann $\mathrm{T}$, et al. Educational intervention to improve physician reporting of adverse drug reactions (ADRs) in a primary care setting in complementary and alternative medicine. BMC Public Health. 2009;9:274.

25. Pimpalkhute SA, Jaiswal KM, Sontakke SD, Bajait CS, Gaikwad A. Evaluation of awareness about pharmacovigilance and adverse drug reaction monitoring in resident doctors of a tertiary care teaching hospital. Indian J Med Sci. 2012;66:55-61.

26. Reddy P, Varma SK, Reddy S. Knowledge, attitude and practice of ADR reporting among clinical residents: A rural medical college survey. J Drug Discov Ther. 2014;2:8-13.

27. Chatterjee S, Lyle N, Ghosh S. A survey of the knowledge, attitude and practice of adverse drug reaction reporting by clinicians in eastern India. Drug Saf. 2006;29:641-2.

28. Datta S, Sengupta S. An evaluation of knowledge, attitude, and practice of adverse drug reaction reporting in a tertiary care teaching hospital of Sikkim. Perspectives in Clinical Research. 2015;6(4):200-6.

29. Cosentino M, Leoni O, Banfi F, Lecchini S, Frigo G. Attitudes to adverse drug reaction reporting by medical practitioners in a Northern Italian district. Pharmacol Res. 1997;35:85-8.

30. Figueiras A, Herdeiro MT, Polónia J, Gestal-Otero JJ. An educational intervention to improve physician reporting of adverse drug reactions: A clusterrandomized controlled trial. JAMA. 2006;296:108693.

31. Gupta SK, Nayak RP, Shivaranjani R, Vidyarthi SK. A questionnaire study on the knowledge, attitude, and the practice of pharmacovigilance among the healthcare professionals in a teaching hospital in South India. Perspectives in Clinical Research. 2015;6(1):45-52.

32. Santosh KC, Pramote T, Gorsanan S, Edwards R. Attitudes among healthcare professionals to the reporting of adverse drug reactions in Nepal. BMC Pharmacol Toxicol. 2013;14(1):14-6.

33. Kira LJ, Shivashankaramurthy KG, Bhooma S, Dinakar KR. Adverse drug reactions reporting among clinician in a teaching hospital South Karnataka. Sch J App Med Sci. 2014;2(1D):399-403.

34. McGettigan P, Feely J. ADR reporting: Opinion and attitudes of medical practitioners in Ireland. Pharmacoepidemiol Drug Saf. 1995;4:355-8.

35. Li Q, Zhang SM, Chen HT, Fang SP, Yu X, Liu D, et al. Awareness and attitudes of healthcare professionals in Wuhan, China to the reporting of adverse drug reactions. Chin Med J. 2004;117:85661. 
36. Upadhyaya HB, Vora MB, Nagar JG, Patel PB. Knowledge, attitude and practices toward pharmacovigilance and adverse drug reactions in postgraduate students of tertiary care hospital in Gujarat. J Adv Pharm Technol Res. 2015;6(1):29-34.

37. Herdeiro MT, Figueiras A, Polónia J, Gestal-Otero J. Physicians' attitudes and adverse drug reaction reporting: a case-control study in Portugal. Drug Saf. 2005;28(9):825-33.

38. Rajesh R, Vidyasagar S, Varma DM. An educational intervention to assess knowledge, Attitude, practice of pharmacovigilance among healthcare professional in an Indian tertiary care teaching hospital. Int $\mathbf{J}$ Pharm Tech Res. 2011;3(2):678-92.

39. Herdeiro MT, Figueiras A, Polónia J, Gestal-Otero JJ. Influence of pharmacists' attitudes on adverse drug reaction reporting: A case-control study in Portugal. Drug Saf. 2006;29:331-40.

40. Klopotowska JE, Wierenga PC, Smorenburg SM, Stuijt CC, Arisz L, Kuks PF, et al. Recognition of adverse drug events in older hospitalized medical patients. Eur J Clin Pharmacol. 2013;69:75-85.

41. Chopra D, Wardhan N, Rehan HS. Knowledge, attitude and practices associated with adverse drug reaction reporting amongstdoctors in a teaching hospital. Int J Risk Saf Med. 2011;23(4):227-32.

Cite this article as: Sen S, Rahaman SR, Chatterjee D, Mukherjee S, Mondal S, Tripathi SK. Knowledge, attitudes and practice of adverse drug reaction monitoring among physicians in India. Int $\mathrm{J}$ Basic Clin Pharmacol 2017;6:1497-506. 